của người công nhân dệt may hiện nay để tìm những điểm bất cập, hạn chế, từ đó đưa ra những khuyến nghị hoặc có giải pháp can thiệp sớm nhẳm cải thiên tình trang dinh dưỡng giúp gia tăng năng suất cho NLĐ nói chung và công nhân dệt may nói riêng.

\section{TÀI LIẸU THAM KHẢO}

1. ILO News (2005), Poor workplace nutrition hits workers' health and productivity, ILO report, GENEVA

2. Lê Bạch Mai (2012), Tình trạng dinh dưỡng, chất lượng an toàn vệ sinh thực phẩm bữa ăn công nhân ở khu công nghiệp - khu chế xuất, Báo cáo tại Hội thảo về thực trạng và giải pháp đảm bảo dinh dưỡng và ATVSTP bữa ăn ca tại $\mathrm{KCN}$ - KCX, Bình Dương.

3. Bô Y tế - Viên Dinh dưỡng (2017), Các phương pháp điều tra khẩu phần, Nhà xuất bản $Y$ học Hà nôii.

4. Viện Dinh dưỡng - Bộ Y tế (2016); Nhu cầu dinh dưỡng khuyến nghị cho người Việt Nam. Nhà xuất bản Y học, Ha Nội.

5. Công Đoàn Cống Thương (2012), Về bũa ăn ca ngưới lao động trọng các doanh nghiệp truy cập tại trang web́: http:// moit.gov.vn/ cdpublic/News/ 10/ve-bua-angiua-ca-cua-nguoi-lao-dong-trongcac-doanh-nghiep.aspx.

6. Meggie Gabida, Notion T. Gombe, Milton Chemhuru và các cộng sự, (2015), Foodborne illness among factory workers, Gweru, Zimbabwe, 2012: a retrospective cohort study, BMC Res Notes, 8, p. 493.

7. Makurat J, Pillai A, Wieringa FT, Chamnan C, Krawinkel MB, (2017), Estimated nutritive value of low-price model lunch sets provided to garment workers in Cambodia, Nutrients, 9:782-799.

8. Trân Thi Minh Hanh và công sự (2013), Năng lượng và các chất dinh dưỡng tiều thụ của công nhân nhập cư tại TPHCM, tạp chí Dinh dưỡng \& thực phẩm, tập 9, số 3.

\title{
TÌM HIỂU MộT SỐ YẾU Tố LIÊN QUAN ĐẾN KẾT QUẢ CHỌC ỐI TRONG CHẨN ĐOÁN TRƯớC SINH TẠI BỆNH VIỆN PHỤ SẢN HẢI PHÒNG
}

\section{TÓM TẮT}

Sàng loc và chẩn đoán trước sinh là phương pháp nhằm phát hiện và chẩn đoán những bất thường của thai về hình thái hoăc di truyền. Mục tiêu: Tìm hiểu một số yếu tố liên quan đến kết quả chọc ối trong chẩn đoán trước sinh tai Bênh viên Phù Sản Hải Phòng. Đối tượng và phương pháp nghiên cứu: có 118 thai phự được tiến hành chọc ối. Kết quả: Có 6 trường hợp nhiếm sắc thể đồ thai nhi bất thường $(5,1 \%)$. Tỷ lệ chọc ối cho kết quả bất thường NST thai nhi nhóm mẹ $\geq 35$ tuổi cao gấp 5,2 lần so với nhóm me $<35$ tuổi $(p<0,05)$. Chọc ối cho kết quả bất thường ở nhóm xét nghiệm sàng lọc nguy cơ cao gấp 1,1 lần so với nhóm thai phụ có xét nghiệm sàng lọc nguy cơ thấp $(p>0,05)$. Siêu âm hình thái thai nhi bất thường có kết quả chọc ối bất thường cao gấp 6,0 lần so với nhóm siêu âm hình thai thai nhi bình thường $(p<0,05)$. Nhóm có tiền sử thai phụ và gia đình bất thường đều có kết quả nhiễm sắc đồ thai nhi bình thường. Kết luâan: Tỷ lệ chọc ối cho kết quả bất thường NST thai nhi ở nhóm me $\geq 35$ tuổi cao gấp 5,2 lần so với nhóm me $<35$ tuổi $(p<0,05)$. Nhóm siêu âm hình thái thai nhi bất thường có kết quả chọc ối bất thường cao gấp 6,0 lần so với nhóm siêu âm hình thai thai nhi bình thường $(p<0,05)$.

Tư khóa: chọc ối, siêu âm hình thái, chẩn đoán trước sinh

*Bệnh viện Phụ sản Hải Phòng

Chịu trách nhiệm chính: Lưu Vũ Dũng

Email: Luuvudung1980@gmail.com

Ngày nhận bài: 23.10.2020

Ngày phản biên khoa họ: 23.11.2020

Ngày duyệt bài: 7.12.2020

\section{Lưu Vũ Dũng*, Vũ Văn Tâm*}

\section{SUMMARY \\ STUDYING SOME FACTORS RELATED TO THE RESULT OF AMNIOCENTESIS IN PRENATAL DIAGNOSIS AT HAI PHONG HOSPITAL OF OBSTETRICS AND GYNECOLOGY}

Prenatal screening and diagnosis are methods to detect and diagnose birth defects as well as genetic disorders. Objectives: studying some factors related to the result of amniocentesis in prenatal diagnosis at HaiPhong hospital of obstetrics and gynecology. Subjects and methods: 118 pregnant women who undergo amniocentesis. Results: There were 6 cases of abnormal fetal chromosomes (5.1\%). The rate of amniocentesis for abnormal fetal chromosomal results in mother group $\geq 35$ years old is 5.2 times higher than that of mother group $<35$ years old $(p<0.05)$. Amniocentesis showed abnormal results in the highrisk-screening group 1.1 times higher than women with low-risk screening tests $(p<0.05)$. Abnormal fetal morphology ultrasound had abnormal amniocentesis is 6 times higher than normal fetal ultrasound group ( $p$ $<0.05$ ). The group with abnormal history of pregnant women and families showed normal fetal chromosomal. Conclusion: The rate of amniocentesis for abnormal fetal chromosome in group mothers $\geq 35$ years old is 5.2 times higher than that of group mothers $<35$ years old $(p<0.05)$. The fetal abnormal ultrasound group had an abnormal amniocentesis is 6.0 times higher than the normal fetal ultrasound group ( $\mathrm{p}<0.05$ ).

Keywords: amniocentesis, morphology ultrasound, prenatal diagnosis.

\section{I. ĐẶT VẤN ĐỀ}

Sàng lọc và chẩn đoán trước sinh là một 
phương pháp mới được ứng dụng ở Việt Nam trong những năm gần đây nhẳm phát hiện và chẩn đoán những bất thường của thai về hình thái cũng như về di truyền.

Ở Việt Nam, chọc ối trong chẩn đoán trước sinh đã được thực hiện từ năm 2003 và tỷ lệ bất thường NST là $11,2 \%$ theo nghiên cứu của tác giả Phùng Như Toàn tại Bệnh viện Từ Dũ [1]. Năm 2004 nghiên cứu của tác giả Hoàng Thị Ngọc Lan và cộng sự tại Bệnh viện Phụ sản Trung ương và Bệnh viện Phụ sản Hà Nội cho thây tỷ lệ bất thường NST là 17,5\% [2]. Theo tác giả Trần Danh Cường (2005), tỷ lệ này ở Bệnh viện Phụ sản trung ương là 11,6\% [3].

Trước thực tế về tình trạng thai dị tật trong cộng đồng, khả năng tiếp cận với các phương pháp chẩn đoán trước sinh một cách hiệu quả và sự chấp nhận cao của xã hội nhất là của các cặp vợ chồng muốn sinh những đứa con khỏe mạnh, tại Bệnh viện Phụ Sản Hải Phòng chúng tôi đã đưa vào hoạt động trung tâm chẩn đoán trước sinh. Các phương pháp chẩn đoán được áp dụng tại trung tâm chúng tôi là siêu âm hình thái thai nhi, xét nghiệm sàng lọc sinh hóa và chọc hút nước ối phân tích nhiềm sắc thể đồ (NSTĐ).

Xuất phát từ thực tế trên, chúng tôi tiến hành nghiên cứu: "Tìm hiểu một số yếu tố liên quan đến kết quả chọc ối trong chẩn đoán trước sinh tại Bệnh viện Phụ Sản Hải Phòng".

\section{II. ĐỐI TƯợNG VÀ PHƯƠNG PHÁP NGHIÊN CỨU}

2.1. Đối tượng nghiên cứu. Tất cả những thai phụ được tiển hành chọc ối xét nghiệm NSTĐ thai nhi, có hồ sơ lưu trữ tại Trung tâm chẩn đoán trước sinh - Bệnh viện Phụ sản Hải Phòng.

- Thời gian nghiên cứu: từ tháng 12/2017 đến tháng 12/2019.

\section{- Tiêu chuân lứa chon:}

+ Thai phụ có chỉ định và loại trừ các chống chỉ định chọc ối.

+ Tất cả các thai phụ và chồng tham gia chọc ối đều tự nguyện và phải ký giấy cam đoan đồng ý chọc ổi, chấp nhận những rủi ro và tác dụng không mong muốn của chọc ối.

+ Hồ sơ ghi chép có đầy đủ các thông tin đáp ứng nội dung nghiên cứu.

+ Trong hồ sơ nghiên cứu phải ghi rõ chỉ định chọc ối và kết quả phân tích NSTĐ thai nhi.

- Tiều chuân loai trư:

+ Thai phụ được chọc ối nhưng không có xét nghiệm NSTÐ thai nhi.

+ Thai phụ có kết quả chọc ối phân tích NSTĐ từ nơi khác.

\subsection{Phương pháp nghiên cứu}

2.2.1.Thiết kế nghiên cứu: Mô tả cắt ngang.

2.2.2. Chỉ số nghiên cứu:

- Tuổi me:

$+\geq 35$ tuổi

$+<35$ tuổi

- Xét nghiệm sàng lọc (XNSL) huyết thanh mẹ:

+ Nguy cơ cao

+ Nguy cơ thấp

- Kêt quả siêu âm hình thái thai nhi:

+ Bình thường

+ Bất thường

- Kết quả nuôi cây tế bào ối phân tích NSTÐ thai nhi:

+ Bình thường

+ Bất thường: Hội chứng Down, Edwards, Patau, Turner, Klinerfelter, thể đa bội, rối loạn cấu trúc nhiễm sắc thể (NST).

2.3. Xử lý số liệu: Dựa trên phần mềm SPSS22.0.

2.4. Đạo đức nghiên cứu:

- Các thông tin cá nhân đều được đảm bảo giữ bí mật.

- Nghiên cứu nhằm mục đích đóng góp vào việc bảo vệ và nâng cao sức khỏe.

\section{KẾT QUẢ NGHIÊN CỨU}

Trong thời gian từ 12/2017 đến tháng 12/2019, tại Bệnh viện Phụ Sản Hải Phòng đã có 118 thai phụ được tiến hành chọc ối, phù hợp với các tiêu chuẩn của đối tượng nghiên cứu.

3.1. Kết quả phân tích nhiễm sắc thể tế bào ối

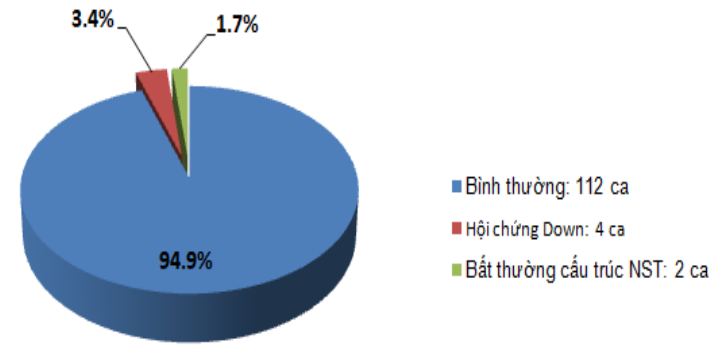

Biểu đồ 3.1. Tỷ lệ bât thường NST trên nhóm đối tượng nghiên cứu

Nhân xét: Trong số 118 mẫu chọc ối:

- Có 112 mẫu chọc ối cho kết quả bình thường chiếm tỉ lệ 94,9\%.

- Chỉ có 06 trường hợp dương tính $(5,1 \%)$ : có 04 trường hợp là hội chứng Down $(3,4 \%) ; 02$ trường hợp là bất thường cấu trúc NST $(1,7 \%)$.

3.2. Mối liên quan của một số yếu tố với kêt quả NSTÐ thai nhi

3.2.1. Liên quan tuổi me với kêt quả NSTO thai nhi 
Bảng 3.1. Liên quan của tuổi mẹ với NSTÐ tế bào ối

\begin{tabular}{|c|c|c|c|c|}
\hline $\begin{array}{c}\text { Tuổi } \\
\text { mẹ }\end{array}$ & \begin{tabular}{|c|} 
Kết quả N \\
Bất thườn \\
$(\mathbf{n}, \%)$
\end{tabular} & $\begin{array}{c}\text { STÐ thai nhi } \\
\begin{array}{c}\text { Bình thường } \\
(n, \%)\end{array}\end{array}$ & OR & $\begin{array}{c}95 \% C \\
\text { I }\end{array}$ \\
\hline$\geq 35$ & $5(8,3)$ & $55(91,7)$ & \multirow{2}{*}{5,2} & $2,3-$ \\
\hline$<35$ & $1(1,7)$ & $57(98,3)$ & & 45,8 \\
\hline
\end{tabular}

Nhận xét: Tỷ lê chọc ối cho kết quả bất thường NSTÐ thai nhi ở nhóm me $\geq 35$ tuổi là $8,3 \%$ cao gấp 5,2 lần so với nhóm mẹ < 35 tuổi là $1,7 \%$. Sự khác biệt có ý nghĩa thống kê với $\mathrm{p}<$ 0,05 .

3.2.2. Liên quan của XNSL không xâm lấn với kêt quá NSTĐ thai nhi

Bảng 3.2. Liên quan giữa XNSL và kêt quả chọc ôi

\begin{tabular}{|c|c|c|c|c|}
\hline \multirow[b]{2}{*}{ XNSL } & \multicolumn{2}{|c|}{$\begin{array}{c}\text { Kết quả NSTÐ } \\
\text { thai nhi }\end{array}$} & \multirow[b]{2}{*}{ OR } & \multirow{2}{*}{$\begin{array}{c}95 \\
\% \mathrm{C} \\
\text { I }\end{array}$} \\
\hline & $\begin{array}{c}\text { Bất } \\
\text { thường } \\
(\mathbf{n}, \%)\end{array}$ & $\begin{array}{c}\text { Bình } \\
\text { thường } \\
(\mathbf{n}, \%)\end{array}$ & & \\
\hline Nguy cơ cao & $5(5,2)$ & $92(94,8)$ & 1,1 & 0,1 \\
\hline
\end{tabular}

Nhân xét: Trong 97 trường hợp choc ôi do có XNSL nguy cơ cao: có 5 trường hợp bất thường NST chiếm tỷ lệ 5,2\% cao gấp 1,1 lần so với nhóm thai phụ có XNSL nguy cơ thấp, tuy nhiên sự khác biệt này không có ý nghĩa thống kế $(p>0,05)$.

3.2.3. Liên quan giữa siêu âm hình thái tới kêt quá NST⿱ thai nhi

Bảng 3.3. Liên quan giữa siêu âm hình thái với kêt quả chọc ôi

\begin{tabular}{|c|c|c|c|c|}
\hline \multirow[b]{2}{*}{$\begin{array}{l}\text { Siêu âm } \\
\text { hình thái }\end{array}$} & \multicolumn{2}{|c|}{$\begin{array}{c}\text { Kết quả NSTÐ } \\
\text { thai nhi }\end{array}$} & \multirow[b]{2}{*}{ OR } & \multirow[b]{2}{*}{$\begin{array}{c}95 \% \\
\text { CI }\end{array}$} \\
\hline & $\begin{array}{c}\text { Bất } \\
\text { thường } \\
(\mathbf{n}, \%)\end{array}$ & $\begin{array}{c}\text { Bình } \\
\text { thường } \\
(\mathbf{n}, \%)\end{array}$ & & \\
\hline Bất thı & $2(22,2)$ & $7(77,8)$ & 6,0 & $3,1-$ \\
\hline
\end{tabular}

Nhân xét: Số trường hợp siêu âm hình thái thai nhi bất thường có kểt quả chọc ối bất thường cao gấp 6,0 lần so với nhóm siêu âm hình thai thai nhi bình thường. Sự khác biệt có ý nghĩa thống kê với $p<0,05$.

3.2.4. Liên quan giữa tiền sử yêu tố nguy cơ và kêt quả NSTÐ thai nhi

Bảng 3.4. Liên quan giữa tiền sử bản thân và gia đình với kêt quả chọc ôi

\begin{tabular}{|c|c|c|}
\hline $\begin{array}{c}\text { Tiền sử bản } \\
\text { thân và gia } \\
\text { đình }\end{array}$ & $\begin{array}{c}|c| \\
\text { Kết quả NSTÐ thai nhi } \\
(\mathbf{n}, \mathbf{\%})\end{array}$ & $\begin{array}{c}\text { Bình thường } \\
(\mathbf{n}, \mathbf{\%})\end{array}$ \\
\hline Bất thường & $0(0,0)$ & $2(100)$ \\
\hline Bình thường & $6(5,2)$ & $110(94,8)$ \\
\hline
\end{tabular}

Nhận xét: Cả 02 trường hợp chọc ối do tiền sử thai phụ và gia đình bất thường đều có kết quả nhiếm sắc đồ thai nhi bình thường, 06 trường hợp kết quả chọc ối bất thường đều là những thai phụ không có gì đặc biệt về tiền sử.

\section{BÀN LUÂN}

4.1. Kết quả phân tích nhiễm sắc thể tế bào ối. Trong nghiên cứu của chúng tôi ở Biểu đồ 3.1 cho thấy trong số 118 trường hợp chọc ối trên những thai phụ có nguy cơ cao sinh con bất thường NST: có 112 mẫu nước ối có NSĐ thai bình thường $(94,9 \%), 06$ NSTĐ thai bất thường được chẩn đoán, chiếm tỷ lệ 5,1\%.

Kết quả nghiên cứu của chúng tôi là tương tự như của tác giả Nguyễn Thị Hoàng Trang[4]. Theo tác giả, tỷ lệ bất thường nhiểm sắc thể chiếm 9,1\%. Nghiên cứu của Trần Danh Cường (2005) tại Bệnh viện Phụ sản Trung ương, tỷ lệ NSTĐ thai bệnh lý rất cao chiếm 42,1\%[3]. Aiexyoi $\mathrm{E}$ cho thấy kết quả NSTĐ thai của 122 trường hợp chọc ối do tăng KSSG là 14,75\% [5]. So với các nghiên cứu trên thì tỷ lệ gặp thai bất thường NST trong nghiên cứu của chúng tôi thấp hơn. Đặng Lê Dung Hạnh [6], chọc ối 140 trường hợp có XNSL nguy cơ cao tìm thấy 9 trường hợp thai bất thường NST với tỷ lệ $6 \%$.

Trong số 06 trường hợp thai bất thường NST: bất thường số lượng NST là 04 trường hợp và bất thường cấu trúc NST là 02 trường hợp. Cả 4 trường hợp bất thường NST đều là Trisomy 21 (hội chứng Down), không gặp bất thường các Trisomy khác như hội chứng Ewards hay hội chứng Patau. Nghiên cứu của tác giả Nguyễn Thị Hoàng Trang cũng cho kết quả tương tự: bất thường về hội chứng Down là 47,5\%[4]. Nghiên cứu của các tác giả Sung-Hee Han [7], Dragoslav Bukvic [8] cũng cho thây tỷ lệ gặp thai hội chứng Down là cao nhất, chiếm $36,9 \%$ và $78,9 \%$ tổng số các trường hợp thai bất thường NST.

Có 02 trường hợp bất thường cấu trúc NST: chiếm 33,3\% các trường hợp kết quả chọc ối bất thường (01 trường hợp là đa hình lặp đoạn vùng dị NST số 1 và 01 trường hợp là mất đầu mút NST X). Theo tác giả Nguyễn Thị Hoàng Trang số trường hợp bất thường về cấu trúc NST chiếm $11,1 \%$. Tỷ lệ này trong nghiên cứu của chúng tôi là cao hơn so với tác giả Nguyễn Hoàng Trang có Iẽ là do sự sai khác trong số lượng đối tượng nghiên cứu [4].

4.2. Mối liên quan của một số yếu tố tới kêt quả NSTĐ thai nhi

Liên quan tuổi me tới kêt quả NSTĐ thai nhi. Kết quả ở Bảng 3.1 cho thấy: bất thường 
NST phát hiên ở $5 / 60$ trường hợp $(8,3 \%)$ trong nhóm mẹ $\geq 35$ tuổi, $01 / 58$ trường hợp $(1,7 \%)$ trong nhóm mẹ <35 tuổi. Tỷ lệ chọc ối cho kết quả bất thường NST thai nhi nhóm me $\geq 35$ tuổi cao gấp 5,2 lần so với nhóm me $<35$ tuổi. Sư khác biệt có ý nghĩa thống kê $(p<0,05)$. Kết quả này tương tự nghiên cứu của Charlotte [9], tỷ lệ thai bất thường NST ở 2 nhóm tuổi me là 10,9\% và $3,2 \%$.

Chúng tôi tin rằng sàng lọc huyết thanh có thể hạn chế được số chọc ối theo tuổi mẹ, nhưng chọc ối vẫn có thể thực hiện trực tiếp trên những trường hợp me lớn tuổi mà không có kết quả sàng lọc huyết thanh.

Liên quan của XNLS không Xâm lấn tới kết quả NSTÐ thai nhi. Theo kết quả nghiên cứu của chúng tôi ở Bảng 3.2, trong số 97 thai phụ có XNSL nguy cơ cao, thai bất thường NST tìm thấy ở 05 trường hợp chiếm tỉ lệ $5,2 \%$, phù hợp theo y văn mô tả tỷ lệ này dao đông từ 1,5\%-10\% [6]. Chọc ối cho kết quả bất thường ở nhóm xét nghiệm sàng lọc nguy cơ cao gấp 1,1 lần so với nhóm thai phụ có xét nghiệm sàng lọc nguy cơ thấp nhưng sự khác biệt này không có ý nghĩa thống kê với p>0,05.

Mục đích của XNSL để sàng lọc nguy cơ thai mắc hội chứng Down, hội chứng Edwards, hở ống thần kinh và phát hiên bất kỳ bất thường NST nào khác. Trong số 97 thai phụ có XNSL nguy cơ cao đã phát hiện được 03 thai mắc hội chứng Down và 02 thai bị bất thường về cấu trúc NST.

Các test sàng lọc trước sinh chính là phòng bệnh cấp 2, giúp phát hiện sớm các trường hợp thai có nguy cơ cao bị bất thường NST hoăc bị dị tâtt bẩm sinh, nhưng để chẩn đoán xác định thì cần tới những kỹ thuât chuyên môn sâu hơnn như chọc ối hay sinh thiết gai rau và gần đây là xét nghiệm NIPT dựa trên cơ sở phát hiện AND của thai trong huyết thanh mẹ[8].

Liên quan giữa siêu âm hinh thái tới kêt quả NSTÐ thai nhi. Kết quả Bảng 3.3 cho thây: 9 trường hợp siêu âm thai có hình ảnh bất thường đơn độc, tức là không kèm theo các yếu tố nguy cơ khác như tuổi me hay XNSL nguy cơ cao... Trong đó có 02 mẫu nước ối có kết quả NST bất thường, chiếm tới $22,2 \%$. Còn ở nhóm siêu âm hình thái học thai nhi bình thường, chỉ có 04/109 trường hợp thai bất thường NST chiếm 3,7\%. Nghiên cứu của tác giả Nguyễn Thị Hoàng Trang cũng cho kết quả tương tự: thai bất thường NST có hình ảnh siêu âm bất thường, chiếm tỷ lệ $26,4 \%$ các trường hợp bất thường NST [4]. Như vây, hình thái học thai nhi bất thường nhờ siêu âm làm tăng nguy cơ thai bất thường NST lên 6,0 lần $(p<0,05)$. Qua đó, có thể nói sàng lọc trước sinh bằng siêu âm hình thái có giá trị dướng tính cao nhất trong số các chỉ định chọc ối. Kết quả này cũng phù hợp với nghiên cứu của nhiều tác giả Việt Nam và trên thế giới.

Kết quả nghiên cứu ở Bảng 3.4 cho thấy: 02 thai phụ chọc ối do có tiền sử đẻ con dị tật hay bất thường NST, tuy nhiên không có trường hợp nào thai bất thường NST được chẩn đoán bởi chọc ối. Có thể do cỡ mẫu của chúng tôi còn hạn chế và không có đầy đủ thông tin về nhiễm sắc đồ của thai phụ và chồng (cả hai trường hợp tiền sử gia đình, bản thân sinh con dị tật này đều không làm công thức NST) nên khó có thể kết luận về nguy cơ thai thật sự bất thường NST trên nhóm đối tượng này. Trong nghiên cứu của tác giả Nguyễn Thị Hoàng Trang chỉ có 4 trường hợp thai phụ và chồng có công thức NST là chuyển đoạn, thì trong cả 4 trường hợp này NSĐ thai đều có kết quả bất thường như của bố hoặc của mẹ[4].

Điều này gợi ý rằng những gia đình có nguy cơ cao sinh con bất thường NST đều nên được làm chẩn đoán trước sinh để có thể ngăn chặn việc cho ra đời những đứa trẻ bị bất thường NST.

\section{KẾT LUÂ̂N}

Tỷ lệ chọc ối cho kết quả bất thường NST thai nhi ở nhóm mẹ $\geq 35$ tuổi cao gấp 5,2 lần so với nhóm mẹ $<35$ tuổi $(p<0,05)$. Nhóm siêu âm hình thái thai nhi bất thường có kết quả chọc ối bất thường cao gấp 6,0 lần so với nhóm siêu âm hình thai thai nhi bình thường $(p<0,05)$.

\section{KIẾN NGH!}

Phương pháp chọc ối, phân tích NST thai nhi được khuyến cáo, áp dụng trong chẩn đoán trước sinh để phát hiện chính xác các thai có dị tật bẩm sinh do di truyền.

\section{TÀI LIẸU THAM KHẢO}

1. Phùng Như Toàn (2003). Khảo sát karyotyp thai nhi qua nuôi cấy tế bào ối trong chẩn đoán tiên sản, Nôii Sản Phu khoa, số đăc biêtt 2003 tr. 278-282.

2. Hoàng Thị Ngọc Lan, Nguyễn Việt Hùng, Trịnh Văn Bảo, Trân Thị Thanh Hướng (2004). Chẩn đoán xác định một số dị tật thai nhi bằng phân tích nhiễm sắc thể tế bào ối nuôi cấy, Tap trí nghiên cứu y hoc, tâp 28 , số 2 , tr. 5-12.

3. Trân Danh Cường (2005). Một số nhận xét về kết quả siêu âm hình thái thai nhi trong chẩn đoán trước sinh tại Bệnh viện Phụ sản Trung ương, Nội san Sản Phụ khoa, sổ đặc biệt, tr. 336-347

4. Nguyến Thi Hoàng Trang (2011). Đáng giá kết quá chọc ối phân tích nhiếm sắc thể thai nhi tại Bệnh viện Phụ Sản Trung Ương 5 năm 2006-2011. Luận văn thạc sỹ y học. Đại học y Hà Nội

5. Aiexyoi $E$ et al (2009). Predictive value of 
increased nuchal translucency as a screening test for the detection of fetal chromosomal abnomalities, ] Matern Fetal Neonatal Med, 22(10): 857-62

6. Đă̆ng Lê Dung Hạnh, Nguyễn Vạn Thông (2007). Đánh giá chương trinh tầm soát hối chứng Down trong thai kỳ bằng xét nghiệm sinh hóa tại Bệnh viện Hùng Vương, Tạp chí Phụ Sản, 03-04, tr.65-79.

7. Sung-Hee Han, M.Đ., Jeong-Wook An, M.T. et al (2008). Clinical and cytogenetic findings on 31.615 mid-trimester amniocenteses, Korean JLab
Med 2008; 28: 378-85.

8. Dragoslav Bukvic, Margherita Fanelli, Guanti Ginevra, Nenad Bukvic (2011). Justifiability of amniocentesis on the basis of positive findings of triple test, ultrasound scan and advanced maternal age, Acta Medica Academica 2017; 40(1): 10-16.

9. Charlotte K Ekelund et al (2008). Impact of a new national screening policy for Down's syndrome in Denmark: population based cohort study, BMJ2008; 337: 1-7.

\section{THỰC TRANG TUÂN THỦ VÊ SINH TAY CỦA NHÂN VIÊN Y TẾ TẠI CÁC KHOA LÂM SÀNG BỆNH VIÊ̂N PHỔI TRUNG ƯƠNG NĂM 2016}

\section{TÓM TẮT}

Nhiễm khuẩn Bệnh viện (NKBV) là hậu quả không mong muốn trong thực hành khám, chữa bệnh và chăm sóc người bệnh. Tỷ lệ nhiễm khuẩn bệnh viện là một trong những chỉ số quan trọng phản ánh chất lượng chuyên môn của bệnh viện, liên quan đến sự an toàn của người bệnh và nhân viên y tế (NVYT); Mục tiêu: Mô tả thực trang kiến thức vê sinh tay (VST'), xác định tỷ lệ tuân thủ thực hành VisT của NVYT tại các khoa lâm sàng Bênh viên Phổi Trung ương năm 2016; Phương pháp nghiển cứu: Tiến cứu, mô tả cắt ngang; Kết quả: Tỷ lệ kiến thức VST của NVYT như sau: Giỏi, khá đạt 80,8 \%; trung bình 19,2\%. Tỷ lệ tuân thủ thực hành VST chung là 55,9\% trong đó tuân thủ theo từng đối tượng là: Bác sĩ đạt 42,3\% ĐD/KTV đạt 59,6\%, Hộ lí đạt 46.9\%. Tỷ lệ tuân thủ thực hành VST ở trình độ cao đẳng là cao nhất đạt $69,3 \%$ và thấp nhất là trình độ sau Đại học đạt 17,9\%, Khối Cấp cứu - Hồi sức tích cực cao nhất đạt $69,1 / \%$, thấp nhất là khối Nội đạt $50,6 \%$. Khoa cao nhất là khoa Hồi sức tích cực đat $72,7 \%$, thấp nhất là Ngoại Tổng hợp đạt 38.8\%; Kết luận: Tỷ lệ kiến thức của NVYT tế đat trên mức trung bình đat $73 \%$, tỷ lệ chung tuân thủ vệ sinh tay đạt $55,9 \%$, tỷ lệ bỏ lỡ cớ hô̂i VST của Bác sĩ $57,7 \%$, trong đó $77,4 \%$ bỏ Iõ cơ hội VST do chưa có phương tiện VST khi khám bệnh, chữa bệnh, chỉ còn $22,6 \%$ bỏ Iõ VST khi có phương tiện VST.

Từ khóa: Tuân thủ, Vệ sinh tay.

\section{SUMMARY \\ CURRENT SITUATION OF HAND HYGIENE COMPLIANCE OF MEDICAL STAFF IN}

\footnotetext{
${ }^{1}$ Bệnh viện Phổi Trung ương

${ }^{2}$ Hôii Lao và Bênh Phổi Việt nam

Chiu trách nhiệm chính: Hoàng Thăng Tùng

Email: hoangtungbvp@gmail.com

Ngày nhận bài: 22.10.2020

Ngày phản biện khoa học: 25.11.2020

Ngày duyệt bài: 8.12.2020
}

\author{
Hoàng Thăng Tùng1, Võ Thị Thanh ${ }^{1}$ \\ Lưu Lan Anh ${ }^{1}$, Đinh Ngọc Sỹ ${ }^{2}$

\section{CLINICAL DEPARTMENTS AT NATIONAL} \\ LUNG HOSPITAL IN 2016
}

Hospital Infection is an unintended consequence of practicing medical care and caring for patients. Hospital infection rates are one of the key indicators that reflect the quality of the hospital's expertise, relative to the safety of patients and medical staff. Objectives: Description of the knowledge with hand hygiene, surveys compliance rate of hand hygiene practices and surveys some related factors to hand hygiene compliance of medical staff at Clinical National Lung Hospital in 2016; Methods: Describe prospective analysis; Results: The rate of hand hygiene knowledge of medical staff as follows: Excellent, and good in 80.8\%; average in $19.2 \%$. Compliance rate overall hand hygiene practices is $55.9 \%$ which comply with each object is: doctors: $42.3 \%$, Nurses / technicians: $59.6 \%$, Nurse's aid: $46.9 \%$. Compliance rate of hand hygiene practices is the highest in collegiat $(69.3 \% 0$ and the lowest of postgraduate qualifications (17.9\%), Division of Emergency and Intensive Care Unit - is highest $(69,1 \%)$, the lowest $(50.6 \%)$ in $f$ the Interior departements. The Intensive Care Unit is the highest $(72.7 \%)$, the lowest was $38.8 \%$ in surgery division. Conclusions: The rate of knowledge of health care workers on an average gain reached $73 \%$, the rate of hand hygiene compliance General 55.9\%, the proportion of missed opportunities of hand hygiene Doctor. $57.7 \%, 77.4 \%$ of which miss the opportunity to hand hygiene by no means hand hygiene when medical examination, treatment and care but the patients, $22.6 \%$ missed only Hand hygiene when sanitation facilities west.

Keyword: Hand hygiene, compliance

\section{I. ĐĂT VẤN ĐỀ}

Nhiễm khuẩn Bệnh viện là hậu quả không mong muốn trong thực hành khám chữa bênh và chăm sóc người bệnh ${ }^{[1],[2]}$. Tỷ lệ NKBV là một trong những chỉ số quan trọng phản ánh chất lượng chuyên môn của bệnh viện, liên quan đến 